Dr. Marina Martín González

Doctoranda en el Programa de Doctorado en Derecho y Ciencias Sociales de la UNED

@ marina@gmprocura.com (iD 0000-0001-7034-7323
Recibido / Received 30 de diciembre de 2018

- Aceptado / Acepted 25 de enero de 2019

- Páginas / Pages De la 37 a la 60

- ISSN: 2531-0054

\title{
La modernización de la relación de los ciudadanos con la Administración de Justicia
}

The modernization of the relationship of citizens with the administration of justice

La generalización del uso de las nuevas tecnologías en todos los sectores de la sociedad ha supuesto una auténtica revolución que ha llegado, no sin retraso, al ámbito jurisdiccional. El presente estudio tiene por objeto exponer el camino recorrido hacia la digitalización de la justicia, profundizar en el contenido del derecho de la ciudadanía a relacionarse por medios electrónicos con la Administración de Justicia y, finalmente, exponer el uso de la tecnología en las comunicaciones entre los justiciables y las oficinas judiciales.

PALABRAS CLAVE: e-justicia, relaciones electrónicas, notificaciones electrónicas, derechos de los ciudadanos ante la Administración de Justicia.

The widespread use of new technologies in all sectors of society has meant an authentic revolution that has come, not without delay, to the Judiciary. The main purpose of this study is to expose the legal path taken towards the digitalization of Justice, deepen the content of the right of citizens to relate by electronic means with the Administration of Justice and, finally, expose the way in which communications between defendants and Judicial Offices are being technified.

KEYWORDS: E-Justice, electronic interaction, electronic service of documents, rights of citizens.

\section{Introducción}

Tradicionalmente, el ámbito jurisdiccional se ha caracterizado por ser uno de los menos permeables ante los avances tecnológicos. Quizá, el miedo a lo desconocido, unido a la preocupación por salvaguardar, ante todo, la integridad de los derechos y garantías procesales en juego -directamente relacionados con el ejercicio del derecho fundamental a la tutela judicial efectiva (art. $24 \mathrm{CE}$ )-, justificaron el inicial escepticismo a la innovación tecnológica. 
En suma, todas estas novedades técnicas parecían amenazar radicalmente la clásica construcción del proceso.

Afortunadamente, a nuestro juicio, en la actualidad, ese temor ha sido superado o, cuando menos suavizado. Las tecnologías de la información y la comunicación (en adelante, TIC), se evidencian como elementos estratégicos para uno de los principales objetivos de las sociedades modernas del siglo xxı: una justicia de calidad más eficaz, independiente, cercana a los ciudadanos y transparente.

La incorporación de medios técnicos, electrónicos, informáticos y telemáticos al funcionamiento ordinario de la Administración de Justicia no solo contribuye a mejorar notablemente la productividad y eficiencia en la tramitación y gestión de los procesos, reduciendo con ello los tiempos de espera, así como los costes; adicionalmente acerca la justicia a la ciudadanía, potenciando su accesibilidad y transparencia. Por lo tanto, es una oportunidad para recuperar la confianza del justiciable en nuestro sistema judicial como medio eficaz y célere para la resolución de conflictos. Esta última es una tarea en la que es fundamental asegurar la plena eficacia del derecho de todos los ciudadanos a relacionarse electrónicamente con la Administración de Justicia.

Sentados los anteriores fundamentos, realizaremos una retrospectiva del proceso de implantación de las tecnologías de la información y la comunicación en el ámbito jurisdiccional. Así, mediante la Ley Orgánica 16/1994, de 8 de noviembre, de reforma de la LOPJ, se introducía, por primera vez en nuestro ordenamiento jurídico, la posibilidad del uso de dichos medios en juzgados, tribunales y fiscalías. Recientemente, destacaremos la oleada legislativa de 2015, que puso en marcha la verdadera cuenta atrás hacia el expediente judicial electrónico. Todo ello, mediante la definitiva implantación del uso obligatorio de los sistemas electrónicos, informáticos y telemáticos existentes para la presentación de escritos y demás documentos, la realización de los traslados de copias y la práctica de los actos de comunicación. Una reforma que transformó profundamente el trabajo diario de los profesionales de la justicia, y que reestructuró el funcionamiento de las Oficinas Judiciales y Fiscales.

A continuación, profundizaremos en el contenido del derecho de los justiciables a interactuar por medios electrónicos con la Administración de Justicia, integrado a su vez, por otros derechos específicos que asisten al usuario en el entorno digital. Valoraremos, asimismo, el grado de implantación real del uso de las nuevas tecnologías en la actuación de los ciudadanos ante las Administraciones Públicas y nos plantearemos la posibilidad de establecer la preceptividad de la vía electrónica en el ámbito jurisdiccional. Una obligación que, por cierto, ya ha sido establecida para determinados sujetos y colectivos que, por razón de su capacidad económica, técnica, profesión u otros motivos, se presume que disponen de los conocimientos y recursos necesarios para asumir tal responsabilidad.

Por último, dedicaremos parte de nuestro estudio a las notificaciones electrónicas. Como no podía ser de otra manera, la incorporación de las TIC al funcionamiento diario de las Oficinas Judiciales y Fiscales ha permitido al legislador replantearse el régimen de actos de comunicación procesal vigente, otorgando plena validez y eficacia jurídicas a las comunicaciones judiciales practicadas por medios electrónicos, informáticos y similares, lo que contribuye, sin duda, a reducir los tiempos de tramitación de los procedimientos y a acercar la justicia a los ciudadanos. 


\section{El proceso de implantación de las TIC en la Administración de Justicia}

En estos últimos tres años, el proceso de modernización de la Administración de Justicia se ha hecho más notorio que nunca. Tras la definitiva generalización del uso de los medios técnicos, electrónicos, informáticos y telemáticos en el ámbito jurisdiccional, con la correlativa obligación para las Oficinas Judiciales y Fiscales, así como para los distintos operadores jurídicos, de adecuar su actividad a una nueva forma de concebir el proceso, hemos alcanzado un punto de no retorno. Ya solo cabe avanzar hacia la Justicia electrónica: un serio compromiso contraído en el año 2015, no tanto como decisión aislada, sino como resultado lógico de un proyecto iniciado hace más de veinte años.

La Ley Orgánica 16/1994, de 8 de noviembre, de reforma de la Ley Orgánica del Poder Judicial, siguiendo los pasos de la Ley 30/1992, de 26 de noviembre ${ }^{1}$, introdujo en nuestro ordenamiento jurídico la esperada habilitación legal necesaria para legitimar el uso de los medios electrónicos en el funcionamiento diario de los juzgados, tribunales y fiscalías. A través de la modificación del artículo 230 LOPJ, se abrieron las puertas al progreso tecnológico y ello permitía poner en marcha la adaptación de sistemas y softwares ya existentes en otros sectores para ponerlos al servicio de una mayor calidad y eficiencia en la Administración de Justicia.

Ahora bien, el camino no estaría libre de obstáculos. El Libro Blanco de la Justicia, elaborado por el Consejo General del Poder Judicial en 1997, subrayaba que dicho encomiable objetivo no pasaría de ser una mera declaración de intenciones, si carecía del debido refuerzo presupuestario, político y legislativo que convirtiera la digitalización de nuestro sistema judicial en una realidad factible ${ }^{2}$.

Desde entonces, la actuación de los poderes del Estado en materia de justicia ha estado presidida por la idea de una justicia moderna, eficaz y tecnológicamente avanzada.

Evidencia destacable de la anterior afirmación es la Ley 1/2000, de 7 de enero, de Enjuiciamiento Civil, con la que se buscaba la agilización, simplificación y modernización de los procedimientos con respecto a su antecesora de 1881 .

1. El artículo 45 de la Ley 30/1992, de 26 de noviembre, del Régimen Jurídico de las Administraciones Públicas y del Procedimiento Administrativo Común, establecía por primera vez que las Administraciones Públicas impulsarían el empleo y aplicación las técnicas y medios electrónicos, informáticos y telemáticos en el desempeño de su actividad y el ejercicio de sus funciones. Asimismo, reconocía la posibilidad de que los ciudadanos hicieran uso de dichos medios en sus relaciones con las Administraciones Públicas. El Real Decreto 263/1996, de 16 de febrero, regularía cuatro años más tarde el uso de las técnicas electrónicas, informáticas y telemáticas por la Administración General del Estado. Con la Ley 39/2015, de 1 de octubre, del Procedimiento Administrativo Común de las Administraciones Públicas, se ha dado otro paso más hacia la generalización del uso de estos medios en el ámbito de las Administraciones Públicas. A lo largo de su articulado, se establece la preferencia de la vía electrónica para la práctica de los actos administrativos, las notificaciones y la tramitación de los procedimientos (vid. arts. 14, 26, 36, 41, 71, 75, entre otros), y su artículo 12.1 recoge la obligación para las Administraciones Públicas de procurar que los ciudadanos dispongan de los canales de acceso, sistemas y aplicaciones necesarios para el ejercicio de su derecho a relacionarse con la Administración por medios electrónicos.

2. Como se explica en el apartado 3.4.1 del Capítulo Cuarto, Sección I, del Libro Blanco de la Justicia, «las previsiones que una futura Ley de Enjuiciamiento Civil pueda hacer respecto de las comunicaciones por medios informáticos, por poner solo un ejemplo, quedarán en letra vacía si no se afronta de forma urgente la provisión de medios a los órganos judiciales. [...] De nada serviría introducir la modificación legal si no se acomete [...] la informatización integral de la Administración de Justicia, la conexión en red de todos los órganos judiciales y la dotación a todos los órganos de los medios precisos que, si en la sociedad de hoy son normales en cualquier organización, por pequeña que sea, se les sigue denominando medios modernos casi de imposible alcance para la Administración de Justicia». 
Asimismo, en la esfera política cabe destacar las propuestas del Pacto de Estado para la Justicia, suscrito el 28 de mayo de 2001, entre el Partido Popular y el Partido Socialista Obrero Español. Entre sus muchos objetivos, este acuerdo abogaba por una reforma integral de la Oficina Judicial a través de la reorganización del trabajo de todos los cuerpos al servicio de la Administración de Justicia. En definitiva, resultaba necesaria la integración de las nuevas tecnologías en la tramitación y la gestión de los procesos, como forma de optimizar los recursos disponibles, ganar en eficiencia y reducir el coste de la actividad jurisdiccional. Un año más tarde, se sancionaría la Carta de Derechos de los Ciudadanos ante la Justicia, suscrita como Proposición no de Ley por unanimidad del Pleno del Congreso de los Diputados el 16 de abril de 2002.

Sin ánimo de extendernos demasiado y centrándonos en la materia que nos ocupa, la siguiente norma de valor trascendental en el proceso de implantación de las TIC en la justicia, sería la conocida Ley 18/2011, de 5 de julio, reguladora del uso de las tecnologías de la información y la comunicación en la Administración de Justicia ${ }^{3}$, instrumento normativo dirigido a compatibilizar el uso de los medios electrónicos con las normas y principios esenciales de nuestro Derecho procesal ${ }^{4}$, consiguiendo, así, trasladar a la praxis y al ámbito procesal la concesión prevista en el artículo 230 LOPJ.

En particular, la mencionada Ley 18/2011, siguiendo los pasos de la Ley 11/2007, de 22 de junio ${ }^{5}$, reguladora del acceso electrónico de los ciudadanos a los servicios públicos en el ámbito de la Administración Pública, en el camino hacia la justicia electrónica, reguló el uso de las TIC en la Administración de Justicia, no solo en su ámbito organizativo interno, sino también, y en especial, en sus relaciones con los ciudadanos, los diversos operadores jurídicos y las demás Administraciones públicas.

En este aspecto, y sin perjuicio de abordar esta cuestión con más detenimiento en el próximo epígrafe, nos gustaría destacar que una de sus más destacables novedades fue el reconocimiento del derecho de los ciudadanos a relacionarse electrónicamente con la Administración de Justicia. Un derecho subjetivo que ya había sido fijado por la Ley 11/2007, de 22 de junio, en el ámbito de las Administraciones Públicas, si bien, carecía de reconocimiento en una norma de rango de Ley en la esfera jurisdiccional. Correlativo a ese derecho, contempló, en su artículo quinto, la obligación de los poderes públicos de garantizar su efectividad mediante la puesta a disposición de las aplicaciones y los sistemas necesarios para su ejercicio.

Cuatro años más tarde, la Ley 42/2015, de 5 de octubre, de reforma de la Ley de Enjuiciamiento Civil, llevaría a cabo una modificación integral de actuaciones procesales clave y pondría fecha al inicio de la primera fase del proceso definitivo de digitalización de la justicia. De este modo, determinó la obligatoriedad del uso de los sistemas informáticos y telemáticos existentes en la Administración de Justicia para la presentación de escritos y documentos y para la realización los actos de comunicación y los traslados de copias, a partir del 1 de enero

3. Aprobada en el marco del Plan Estratégico de Modernización de la Justicia para 2009-2012, aprobado el 12 de noviembre de 2008 por el Pleno del Consejo General del Poder Judicial.

4. En este sentido, Cotino Hueso, L. y Montesinos García, A. (2012), «Derechos de los ciudadanos y los profesionales en las relaciones electrónicas con la Administración de Justicia», en Valero Torrijos, J. y Gamero Casado (coord.), Las tecnologías de la información y la comunicación en la administración de justicia: análisis sistemático de la Ley 18/2011, de 5 de julio, Cizur Menor, Aranzadi, 1. a edición, p. 183.

5. Ley actualmente derogada, junto con la Ley 30/1992, de 26 de noviembre, por la reciente Ley 39/2015, de 1 de octubre, del Procedimiento Administrativo Común. 
de 2016. Una obligación, en principio, restringida a los profesionales del Derecho y a las Oficinas Judiciales y Fiscales, que se extendería, desde el 1 de enero de 2017, a todos aquellos colectivos que, por razón de su capacidad económica, técnica, dedicación profesional u otros motivos, tuvieren acceso y disponibilidad de los medios electrónicos necesarios para una interacción electrónica en el ámbito jurisdiccional.

Al tiempo, esta reforma potenciaba la relación electrónica de los ciudadanos con la Administración Justicia, reconociéndoles la posibilidad de optar, a partir de enero de 2017, por la recepción de notificaciones o la realización de determinadas actuaciones judiciales vía electrónica. Medidas todas para cuya efectividad devino fundamental la creación y puesta en marcha de las sedes judiciales electrónicas ${ }^{6}$ : plataformas a través de las cuales se canaliza el ejercicio del derecho de los ciudadanos a interactuar electrónicamente con las Oficinas Judiciales.

En buena lógica, fue aprobado el Real Decreto 1065/2015, de 27 de noviembre, sobre comunicaciones electrónicas en la Administración de Justicia en el ámbito territorial del Ministerio de Justicia y por el que se regula el sistema LexNET, por el que se desarrolla la Ley 18/2011 y se deroga el Real Decreto 84/2007, de 26 de enero. En él se regulan diversos aspectos relativos a la seguridad de las comunicaciones, así como a la disponibilidad y funcionamiento de los distintos canales electrónicos previstos para los usuarios de la Administración Judicial electrónica para la presentación de escritos, la práctica de notificaciones y la realización de los traslados de copias.

Para finalizar nuestra breve exposición sobre los principales hitos normativos en la modernización de nuestro sistema judicial, debemos remitirnos a la Ley Orgánica 7/2015, de 21 de julio, por la que se modifica la Ley Orgánica del Poder Judicial. En relación con la materia que nos ocupa, alteró el tenor literal del artículo 230 LOPJ, con el fin de disponer la obligatoriedad para juzgados, tribunales y fiscalías del empleo de los medios técnicos, electrónicos, informáticos y telemáticos puestos a su disposición para el desarrollo de su actividad y el ejercicio de sus funciones. Esta modificación sería la base de la Ley 42/2015, de 5 de octubre, sancionada pocos meses más tarde. Por su parte, fue incluido un nuevo capítulo en el Título III del Libro III de la Ley Orgánica del Poder Judicial, sobre la "protección de datos de carácter personal en el ámbito de la Administración de Justicia»" ${ }^{7}$, con el que se daba respuesta a la necesidad de contar con una regulación específica en esta materia.

Veinte años después, la tecnificación de la justicia es aún un objetivo inconcluso. En definitiva, es un reto complejo, que reclama un severo compromiso político a medio y largo plazo, la implicación directa de todos los sujetos afectados y, por supuesto, de la ciudadanía, que deberá depositar su confianza en las nuevas herramientas digitales para la defensa de sus derechos e intereses legítimos. En todo caso, este proyecto exige una dotación de medios materiales y humanos suficientes para garantizar su operatividad y eficacia. Si bien somos optimistas sobre los importantes avances alcanzados en los últimos años, no podemos ocultar el largo trecho que aún hemos de recorrer.

6. Por la Orden JUS/1126/2015, de 10 de junio, se creó la sede judicial electrónica correspondiente al ámbito territorial del Ministerio de Justicia (actualmente se refiere al Tribunal Supremo, Audiencia Nacional y las Comunidades Autónomas de Extremadura, Castilla-La Mancha, Castilla y León, Islas Baleares, Región de Murcia, Ceuta y Melilla).

7. En virtud del Artículo Único. 36 de la Ley Orgánica 7/2015, de 21 de julio, se incluye un nuevo «Capítulo I Bis» en el Título III del Libro III, que comprende los artículos 236 bis a 236 decies: «La protección de datos de carácter personal en el ámbito de la Administración de Justicia». 


\section{El estatuto jurídico del ciudadano en sus relaciones electrónicas con la Justicia}

\subsection{Derechos reconocidos por la Ley 18/2011, de 5 de julio, reguladora del uso de las tecnologías de la información y la comunicación en la Administración de Justicia}

La implantación y generalización del uso de las nuevas tecnologías en el ámbito jurisdiccional ha traído consigo la posibilidad de ofrecer al ciudadano un nuevo modo de relacionarse con la Administración de Justicia: la vía electrónica.

Aunque pueda parecer extraño, esta opción ya se contemplaba en el artículo 230 LOPJ en su redacción dada por la Ley Orgánica 16/1994, de 8 de noviembre. En efecto, su apartado 4.ำ reconocía -y sigue reconociendo ${ }^{8}$ - para los justiciables la posibilidad de emplear medios técnicos, electrónicos, informáticos y telemáticos en su actuación ante la Administración de Justicia, siempre y cuando fueran compatibles con aquellos que dispusieran los órganos jurisdiccionales y con pleno respeto de las garantías y formalidades procesales rectoras del procedimiento en cuestión.

Pese a que en aquel momento dicha obligación carecía de virtualidad práctica, dado que el proceso de modernización se encontraba aún en un estado incipiente, lo cierto es que esta disposición evidencia la perfecta consciencia de que el estatuto jurídico del ciudadano se vería afectado por la tecnificación de nuestro sistema judicial ${ }^{9}$.

El primer texto que recogió de forma expresa el derecho de los ciudadanos a optar por la vía electrónica en el ámbito jurisdiccional, junto con el correlativo deber para los poderes públicos españoles de impulsar el empleo de tales medios en el desarrollo de la actividad de los Juzgados y Tribunales, fue la Carta de Derechos de los Ciudadanos ante la Administración de Justicia ${ }^{10}$. Esta Carta, fue aprobada como Proposición no de Ley por unanimidad del Pleno del Congreso de los Diputados el 22 de abril de 2002. No obstante, al tratarse de una iniciativa parlamentaria, habría que esperar a la entrada en vigor de la Ley 18/2011, de 5 de julio, para sostener el reconocimiento de un auténtico derecho subjetivo previsto en una norma de rango de ley, lo que, esta vez sí, obligaba a las autoridades públicas a disponer de las medidas adecuadas y precisas para dotar de eficacia a este derecho ${ }^{11}$.

En virtud del artículo 4.1 de la Ley 18/2011, de 5 de julio, «los ciudadanos tienen derecho a relacionarse con la Administración de Justicia utilizando medios electrónicos para el ejercicio de los derechos previstos en los Capítulos I y VII del Título III del Libro III de la Ley

8. El contenido del apartado 4. ${ }^{\circ}$ del artículo 230 LOPJ no fue modificado con la reforma introducida por la Ley Orgánica $7 / 2015$, de 21 de julio.

9. Como explica González Campo, el uso de las nuevas tecnologías supone «una auténtica revolución que modifica profundamente los hábitos conductuales de los individuos, sus derechos y obligaciones e incluso el modo en que la Administración se relaciona con el ciudadano». En González Campo, F. (2012), “Configuración procesal del Expediente Judicial Electrónico: Hacia un Derecho procesal electrónico», en Bueno de Mata, F. (coord.), FODERTICS: Estudios sobre Derecho y Nuevas Tecnologías, Santiago de Compostela, Andavira, p. 201.

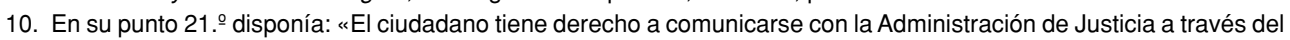
correo electrónico, videoconferencia y otros medios telemáticos con arreglo a lo dispuesto en las Leyes procesales. Los poderes públicos impulsarán el empleo y aplicación de estos medios en el desarrollo de la actividad de la Administración de Justicia, así como en las relaciones de esta con los ciudadanos».

11. En este sentido, Cotino Hueso, L. y Montesinos García, A. (2012, p.189). 
Orgánica 6/1985, de 1 de julio, del Poder Judicial ${ }^{12}$, en la forma y con las limitaciones que en los mismos se establecen».

Un sector doctrinal, como Cotino Hueso y Montesinos García, califican como «deficiente» la remisión en bloque que realiza esta norma categórica a los preceptos de la Ley Orgánica del Poder Judicial, al resultar «reiterativa y aportar poco o nada al derecho ya reconocido», e «insuficiente, dado que el reconocimiento de un derecho en su contexto electrónico hubiera requerido de una regulación concreta para ser efectivo» ${ }^{13}$. En efecto, como veremos seguidamente, se constata cierta duplicidad entre algunos de los derechos a los que remite el apartado 1. del artículo 4 y los que, posteriormente, se relacionan en su apartado 2. En cuanto a derechos como el de publicidad de las actuaciones (art. 229.2 LOPJ) o el uso de las lenguas oficiales de las Comunidades Autónomas (art. 231.3 LOPJ) ${ }^{14}$, sus previsiones son, cuando menos, insatisfactorias en cuanto al modo y condiciones en que va a «trasladarse» el ejercicio de dichos derechos al entorno digital.

Junto con el derecho general a relacionarse con la Administración de Justicia por medios electrónicos, el cual implica la posibilidad de optar, libremente, por el tradicional canal presencial o por las nuevas vías tecnológicas, el mencionado artículo 4 de la Ley 18/2011 enumera, en su apartado 2.ํ, una serie de derechos específicos e inherentes a la elección y utilización de los medios electrónicos en la actividad judicial. Para agilizar la exposición, los clasificaremos en tres grupos:

En primer lugar y relacionados con el acceso electrónico a los servicios ofrecidos, cabe destacar:

a) El derecho a elegir, entre aquellos que estén disponibles, el canal a través del cual prefieren relacionarse electrónicamente con la Administración de Justicia (4.2.a).

b) El derecho a escoger las aplicaciones o sistemas para llevar a cabo dicha interacción, siempre y cuando utilicen estándares abiertos ${ }^{15}$ o sean de uso generalizado por la ciudadanía y, en todo caso, sean compatibles con aquellos de los que dispongan los órganos judiciales y sean respetuosos con las normas y garantías reguladoras del proceso (4.2.i).

c) El derecho a la igualdad en el acceso a los servicios electrónicos (4.2.b).

Este último derecho, en su doble vertiente ${ }^{16}$, exige, por un lado, que los ciudadanos accedan en condiciones de igualdad a los servicios ofrecidos, con independencia de su elección

12. Bajo la rúbrica "De las actuaciones judiciales», el Título III del Libro IIII de la LOPJ dedica su Capítulo I a la «oralidad, publicidad y lengua oficial» (arts. 229-236); y su Capítulo VII a las «notificaciones» (arts. 270-272).

13. Cotino Hueso, L. y Montesinos García, A. (2012, p. 200).

14. Ejemplos señalados por Cotino Hueso, L. y Montesinos García, A. (2012, P. 201).

15. Este derecho se encuentra íntimamente relacionado con el «principio de neutralidad tecnológica», el cual se recogía expresamente en el artículo 4 de la Ley 11/2007, de 22 de junio, de acceso electrónico de los ciudadanos a los Servicios Públicos, en un listado de principios generales que, por cierto, echamos de menos en la Ley 18/2011. En virtud de este principio inspirador del uso de las tecnologías en la Administración, los poderes públicos deben salvaguardar «la independencia en la elección de las alternativas tecnológicas por los ciudadanos».

16. Un reflejo de esta doble vertiente del derecho a la igualdad en el acceso a los servicios electrónicos lo encontramos en el artículo 5 de la Ley 18/2011, de 5 de julio, en virtud del cual: «1. Las Administraciones con competencia en materia de justicia habilitarán diferentes canales o medios para la prestación de los servicios electrónicos, asegurando, en todo caso, el acceso a los mismos a todos los ciudadanos, con independencia de sus circunstancias personales, medios o conocimientos, en la forma que estimen adecuada». 
tecnológica ${ }^{17}$; y, por otro lado, que se facilite el acceso a todos los ciudadanos y, en especial, a aquellas personas y colectivos que, por razón de sus circunstancias personales, medios o conocimientos, encuentren una mayor dificultad para adaptarse al uso de las nuevas tecnologías (DA 3.ำ RD 1065/2018).

En definitiva, la característica común de todos estos derechos es que, para no quedar vacíos de contenido, requieren de una actuación activa por parte de las Administraciones con competencia en materia de justicia, tendente a garantizar, además del acceso en sí, la existencia de diversos canales, sistemas y aplicaciones de acceso plenamente operativos entre los que poder elegir ${ }^{18}$.

Como explica Cerrillo-i-Martínez, en relación con la digitalización de las Administraciones Públicas, «la eficacia de la mayoría de los derechos previstos se ha visto en muchos casos limitada, no tanto por su propia configuración jurídica, sino por otros motivos como la falta de información o conocimiento sobre su existencia entre la ciudadanía, de comunicación entre las Administraciones públicas o de recursos humanos y técnicos suficientes para garantizar su cumplimiento ${ }^{19}$.

No estamos ante un objetivo sencillo. La asunción de competencias por parte de muchas Comunidades Autónomas ${ }^{20}$ en materia de "administración de la Administración de Justicia» ${ }^{21}$ ha propiciado que el proceso de tecnificación de nuestro sistema judicial siga un ritmo desacompasado, ofreciéndose a los justiciables un abanico de servicios y canales electrónicos distinto en función del territorio desde el que pretendan acceder ${ }^{22}$.

La igualdad efectiva de todos los ciudadanos en sus relaciones electrónicas con la Administración de Justicia pasa por que las distintas Administraciones con competencia en la materia cooperen y coordinen su actuación a la hora de trasladar al plano fáctico los pla-

17. En el ámbito de las Administraciones Públicas, el artículo 41 de la Ley 11/2007, de 22 de junio, disponía: «Las Administraciones Públicas utilizarán las tecnologías de la información en sus relaciones con las demás administraciones y con los ciudadanos, aplicando medidas informáticas, tecnológicas, organizativas, y de seguridad, que garanticen un adecuado nivel de interoperabilidad técnica, semántica y organizativa y eviten discriminación a los ciudadanos por razón de su elección tecnológica».

18. Simón Castellano, P. (2012), «El derecho a la relación electrónica con la Administración de Justicia con la Ley 18/2011: un estudio crítico", en Bueno de Mata, F. (coord.), FODERTICS: Estudios sobre Derecho y Nuevas Tecnologías, Santiago de Compostela, Andavira, p. 379.

19. Cerrillo-i-Martínez, A. (2011), «¿Cómo facilitar el ejercicio de los derechos de los ciudadanos en la Administración electrónica?», Revista de Internet, Derecho y Política IDP, n. 13, p. 32. Revista electrónica disponible en: https://goo. gl/Wx67Dp. Última consulta: 26/12/2018.

20. Comunidades Autónomas con competencias transferidas: Andalucía, Aragón, Principado de Asturias, Canarias, Cantabria, Cataluña, Comunidad Valenciana, Galicia, Comunidad de Madrid, Comunidad Foral de Navarra, País Vasco, La Rioja. Véase «Reales Decretos de traspaso en materia de Administración de Justicia», Ministerio de Justicia. Disponible en: https://goo.gl/jmJNQa. Última consulta: 23/12/2018.

21. En sus sentencias 56/1990, de 29 de marzo, y 62/1900, de 30 de marzo, el Tribunal Constitucional sentó las bases para la asunción de competencias por las Comunidades Autónomas en materia de Administración de Justicia. En este sentido, diferenció, por un lado, aquellas materias directamente relacionadas con la actividad jurisdiccional (art. $117 \mathrm{CE}$ ), que son competencia exclusiva del Estado (art. 149.1. 5. CE); y, por otro lado, todo lo relacionado con la actividad administrativa al servicio de la Administración de Justicia (“administración de la Administración de Justicia»), materia no reservada en exclusiva al Estado y respecto a la que, por lo tanto, las Comunidades Autónomas podían asumir competencias. Esta interpretación permite a las mencionadas Comunidades Autónomas tomar decisiones sobre cuestiones, a nuestro parecer, tan trascendentales como la organización y dotación de los medios materiales y humanos. En Aparicio Pérez, M. A. (2011), «Las competencias autonómicas en materia de Administración de Justicia», revista Abogados, n. .68 , septiembre de 2011, pp. 44-47.

22. En este sentido, véase Fundación Telefónica (2009), Las TIC en la Justicia del futuro, Colección Fundación Telefónica, Cuaderno 21, Madrid, Ariel, p. XXVIII. 
nes de modernización, comprometiéndose a poner a disposición de la e-justicia los medios materiales y humanos adecuados y suficientes para ofrecer a los ciudadanos una carta de servicios y un listado de canales, sistemas y aplicaciones de acceso uniformes, operativos e interoperables a nivel nacional.

Volviendo al listado de derechos contemplado en el artículo 4.2 de la Ley 18/2011, relacionados con el acceso a la información judicial, es aquí donde encontramos cierta duplicidad entre los derechos recogidos en la Ley Orgánica del Poder Judicial a los que nos remite el apartado 1. del artículo 4 y los previstos en este apartado. Así:

a) El derecho a conocer por medios electrónicos el estado de los procedimientos en los que sean partes procesales legítimas (4.2.c).

b) El derecho a obtener copias digitales de los documentos electrónicos que conformen el expediente judicial por quienes sean parte o acrediten interés legítimo (4.2.d).

c) El derecho a la conservación en formato electrónico de todos aquellos documentos de esa misma naturaleza que conformen el expediente judicial, de acuerdo con la normativa vigente de archivos judiciales (4.2e).

Por supuesto, el ejercicio de todos ellos se materializará conforme a las disposiciones y limitaciones contenidas en la legislación procesal en vigor. Debemos tener muy presente que el uso de los medios electrónicos en el ámbito jurisdiccional no puede implicar, en ningún caso, la inobservancia de las normas rectoras del proceso ${ }^{23}$. Antes bien, todo lo contrario, es en el entorno digital donde los derechos y garantías esenciales del proceso se encuentran más expuestos y ello nos obliga a procurar con suma prudencia la perfecta adecuación del empleo de las nuevas tecnologías al Derecho procesal.

Por lo tanto, en lo que respecta al derecho de acceso a la información judicial, debemos señalar que los titulares del mismo seguirán siendo aquellos legitimados por la legislación procesal, con independencia de que su ejercicio se lleve a cabo por medios digitales o por la vía presencial. Para ello, deberán desarrollarse e implantarse medidas de seguridad que aseguren la integridad y confidencialidad de la información contenida en el expediente judicial electrónico e impidan el acceso ilícito y su consulta por cualquier sujeto no autorizado ${ }^{24}$.

Relacionados, precisamente, con la seguridad de las comunicaciones electrónicas, destacamos: el derecho a utilizar los sistemas de identificación y firma electrónica contenidos en el DNI-e o cualquier otro reconocido para la realización de trámites electrónicos (4.2.f); y el derecho a la seguridad y la confidencialidad de los datos que figuren en ficheros, sistemas y aplicaciones de la Administración de Justicia en los términos de la Ley Orgánica 3/2018, de 5 de diciembre, de protección de datos personales y garantía de los derechos digitales $(4.2 . g)^{25}$.

23. Esta es otra dimensión del principio de neutralidad tecnológica, al que González Campo (2012, p. 211) se refiere como la condición de que «el uso de medios o procedimientos electrónicos no pueda alterar la naturaleza, condición o derechos de las partes, ni el modo en que la Ley procesal conforma un determinado proceso o tramitación».

24. En esta materia, destacamos Mira Ros, C. (2012), «Algunas reflexiones sobre la protección de datos personales en el ámbito judicial», Repositorio Universidade da Coruña. Disponible online en: https://goo.gl/zJL9wf. Última consulta:29/12/2018. 25. El artículo 4.2.g, de la Ley 18/2011, de 5 de julio, hace referencia expresa a la Ley Orgánica 15/1999, de 13 de diciembre, de Protección de Datos de Carácter Personal, si bien, dado que esta norma ha sido derogada recientemente por la Disposición Derogatoria Única de la Ley 3/2018 de 5 de diciembre, de Protección de Datos Personales y garantía de los derechos digitales, entendemos que las remisiones a la antigua normativa pasan a la nueva. 
Finalmente, se incluye el derecho a la calidad de los servicios públicos prestados por medios electrónicos (4.2.h), derecho este, a nuestro entender, excesivamente etéreo e indefinido, por lo que, más que ante un derecho subjetivo concreto y exigible, parece que nos encontramos ante una mera declaración programática ${ }^{26}$ por el que se obliga a los poderes públicos a adoptar todas aquellas medidas que redunden en beneficio de la calidad de los servicios electrónicos ofrecidos en el seno de la Administración de Justicia.

En suma, y con Cotino Hueso y Montesinos García, sı bien la Ley 18/2018 no regula ni desarrolla el ejercicio del derecho fundamental a la tutela judicial efectiva, al reconocerse nuevos derechos y posiciones jurídicas vinculados a la relación electrónica de los ciudadanos con la Administración de Justicia, estos pasan a convertirse en «elementos instrumentales» de aquel derecho fundamental, con lo que su negación, falta o insuficiencia sí que podría terminar por conllevar una lesión reconocible en sede constitucional ${ }^{27}$.

\subsection{Voluntariedad versus deber del uso de los medios electrónicos en el ámbito de la Administración de Justicia}

El derecho a optar por la vía electrónica para relacionarse con la Administración de Justicia implica, en su formulación negativa, el derecho a no hacerlo por medios electrónicos en el ámbito jurisdiccional y optar por la vía presencial.

A diferencia de los profesionales de la justicia, expresamente obligados al uso de los medios electrónicos establecidos por las Administraciones con competencia en materia de justicia en el desarrollo de su actividad profesional (art. 6.3 LUTICAJ, art. 273 LEC, art. 5 RD 1065/2015), nuestra legislación no prevé para la ciudadanía en términos generales, un deber de interactuar electrónicamente con la Oficina Judicial, sin perjuicio de aquellos sujetos y colectivos que, como veremos, sí pesa sobre ellos esta obligación.

Tal y como dispone el apartado 2. del artículo 273 LEC, en su redacción dada por la renombrada Ley $42 / 2015$, de 5 de octubre, «las personas que no estén representadas por procurador podrán elegir en todo momento si actúan ante la Administración de Justicia a través de medios electrónicos o no, salvo que estén obligadas a relacionarse a través de medios electrónicos con la misma. El medio elegido podrá ser modificado en cualquier momento». Se trata del "derecho a la intermodalidad», reconocido también en el artículo 33.1 de la Ley 18/2011. En virtud de este derecho, el justiciable tiene la libertad de elegir el modo en que quiere relacionarse con la Administración de Justicia, ya sea presencial o electrónico y, por

26. Tomando como referencia la reflexión de Cotino Hueso en relación con el reconocimiento de este derecho por la Ley 11/2007 en el ámbito de la Administración Pública: «El reconocimiento de este derecho tiene un componente simbólico, más que el propio componente jurídico. El reconocimiento de la calidad como derecho subjetivo conlleva importantes problemas para la determinación de su contenido y alcance. No es sencillo prever cuándo podría considerarse vulnerado este derecho. En tanto en cuanto se dan exigencias concretas para lograr la calidad en la Administración y en concreto en la LAE, cabe pensar que siempre que pudiera considerarse afectado un ciudadano en su esfera de intereses por esta causa, podría acudirse a este derecho». En Cotino Hueso, L. (2010), «El derecho a relacionarse electrónicamente con las Administraciones y el estatuto del ciudadano e-administrado en la Ley 11/2007 y la normativa de desarrollo", en Gamero Casado, E. y Valero Torrijos, J. (coord.), La Ley de Administración electrónica. Comentario sistemático a la Ley 11/2007, de 22 de junio, de acceso electrónico de los ciudadanos a los Servicios Públicos, Cizur Menor, Aranzadi,

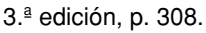

27. Cotino Hueso, L. y Montesinos García, A. (2012, p. 183). 
supuesto, de forma no vinculante, esto es, pudiendo acudir a otro canal electrónico diferente, o a la vía presencial, en el momento que considere oportuno. Eso sí: a nuestro juicio, siempre y cuando ello sea posible conforme a las normas procesales rectoras del procedimiento judicial en cuestión y los medios electrónicos disponibles y compatibles con aquellos de los que disponen las Oficinas Judiciales lo permitan.

Algunos autores han criticado que no se hayan establecido límites concretos al ejercicio de este derecho a la intermodalidad. Críticas fundadas, en opinión de Cernada Badía ${ }^{28}$, «en su excesivo garantismo y su escasa practicidad para la gestión de los procesos». En efecto, es cierto que podría resultar especialmente gravoso para el personal al servicio de la Administración de Justicia que una de las partes procesales cambiase de parecer (reiteradamente) sobre el canal a través del cual prefiere, por ejemplo, recibir los actos de comunicación judicial. En estos casos, nos situaríamos ante el riesgo de duplicidades, dilaciones innecesarias e, incluso, inseguridad jurídica respecto a la validez y eficacia jurídicas de las comunicaciones practicadas por uno u otro medio. Una solución razonable ${ }^{29}$ podría ser la contemplada en el artículo 152.1 LEC para los supuestos en los que se cambie de opinión acerca de la elección inicial de que todos los actos de comunicación se practiquen por el Procurador. En este sentido, el mencionado precepto dispone: «los solicitantes podrán, de forma motivada y concurriendo justa causa, pedir la modificación del régimen inicial, procediendo el Letrado de la Administración de Justicia, si lo considera justificado, a realizar los sucesivos actos de comunicación conforme a su nueva petición».

En cualquier caso, esta libertad de elección reconocida al ciudadano se encuentra justificada por un factor esencial: la necesidad de garantizar el acceso a la Justicia. En el ámbito jurisdiccional, resultaría inconcebible que una persona viera negado su derecho fundamental a la tutela judicial efectiva por no disponer o desconocer el funcionamiento de las nuevas herramientas tecnológicas implantadas en la Administración de Justicia, sin que se le ofreciera, si quiera, una alternativa para comparecer y actuar en defensa de sus derechos e intereses legítimos. Ello situaría, sin lugar a duda, a gran parte de la población en una seria situación de indefensión. Nos remitimos a los datos:

1. Pese a que el número de personas que usan Internet $(86,4 \%$, entre la población de 16-74 años) es amplio ${ }^{30}$, el empleo de este canal para interactuar con las Administraciones o acceder a servicios públicos ofrecidos online $(65,4 \%)$ debería mejorar para poder hablar de una auténtica generalización del uso de los medios electrónicos entre

28. Cernada Badía (2016), «La notificación judicial electrónica: garantía del derecho fundamental a la tutela judicial efectiva y retos que plantea a la Administración de Justicia en España», Tesis Doctoral dirigida por el Dr. Lorenzo Cotino Hueso, Facultad de Derecho de la Universidad de Valencia, Valencia, 2016, p. 250. Disponible en: https://goo.gl/gDJFJc. Última consulta: 29/12/2018.

29. Cernada Badía (2016, p. 250-251) señala algunas alternativas propuestas por la doctrina como, por ejemplo, que la elección del medio electrónico «sea vinculante para el ciudadano, eso sí, siempre limitada a la tramitación del procedimiento para el cual se efectuó la elección», o bien, que se limite «el carácter vinculante de la elección del medio a la instancia concreta para la cual se efectuó la elección, pudiéndose cambiar de medio en otras instancias, al variar uno de los sujetos de la relación electrónica». Citando, entre otros a Pacheco Cifuentes, A. (2011), «Luces y sombras del expediente judicial electrónico», luris: Actualidad y práctica del Derecho, n.ำ160, p.22.

30. Datos extraídos de la encuesta sobre equipamiento y uso de tecnologías de información y comunicación en los hogares del Instituto Nacional de Estadística, cuyos resultados fueron publicados el pasado 7 de noviembre de 2018. Disponible en: https://goo.gl/k6pvLZ. Última consulta: 24/12/2018. 
la ciudadanía en el ámbito de las Administraciones Públicas ${ }^{31}$. De entre las principales acciones que llevan a cabo los ciudadanos en la Administración electrónica podemos destacar en el primer puesto la obtención de información (56,6\%), seguida por la presentación de formularios cumplimentados $(47,2 \%)$ y, en tercer lugar, la descarga de formularios oficiales $(44,5 \%)$, no ofreciéndose datos sobre la tramitación de procedimientos electrónicos.

2. En relación con la disposición y empleo de medios cualificados de seguridadi22, los cuales resultan básicos para garantizar la seguridad de las comunicaciones electrónicas, y más en un entorno como el jurisdiccional, los resultados son más desalentadores, siendo considerablemente limitado el uso de dichos medios por la población. En concreto: DNI-e (12,3\%) y certificados digitales $(21,5 \%)$. Uno de los principales motivos alegados para la no utilización de estas medidas de seguridad es «no necesito o no me interesa» (53,5\% respecto al DNI-e y 45,3\% respecto al certificado digital), resultándonos, asimismo, especialmente llamativos los resultados obtenidos por las respuestas «no sé lo que es» y «no me da confianza, no me da seguridad» (17,6\% respecto al DNI-e y $26,8 \%$ respecto al certificado digital). No hace falta decir que estamos ante una asignatura pendiente. La deficiente generalización del empleo de estos medios, así como la falta de conocimientos sobre su manejo y trascendencia en las relaciones electrónicas, es patente.

A pesar de todo, si comparamos estos datos con los obtenidos en años anteriores, podemos constatar un gran avance hacia la e-Administración. Sin embargo, se constata que la ciudadanía, en general, no estaría preparada para asumir la obligatoriedad del uso de los medios electrónicos en la Administración de Justicia, sin que se viera seriamente comprometido el derecho fundamental a la tutela judicial efectiva y, más concretamente, el derecho de acceso a la Justicia.

¿Qué ocurre, en este sentido, con los nuevos sujetos y colectivos obligados al uso de dichos medios? ¿Están realmente preparados para asumir dicho compromiso?

De conformidad con el artículo 273.3 LEC, reformado, por supuesto, por la Ley $42 / 2015$, de 5 de octubre, «en todo caso, estarán obligados a intervenir a través de medios electrónicos con la Administración de Justicia, al menos, los siguientes sujetos: personas jurídicas; entidades sin personalidad jurídica; quienes ejerzan una actividad profesional para la que se requiera colegiación obligatoria, para trámites y actuaciones realizadas en ejercicio de su profesión; notarios y registradores; quienes representen a un interesado que esté obligado a relacionarse electrónicamente con la Administración de Justicia; los funcionarios de las Administraciones Públicas, para trámites y actuaciones realizadas por razón de su cargo».

31. Estos datos reflejan la interactuación electrónica con las Administraciones, en general, no específicos del ámbito judicial. Dada la reciente generalización del uso de las TIC en el ámbito de la Administración de Justicia, el nivel de interactuación electrónica ciudadana con las Oficinas Judiciales puede que sea, de momento, más limitado. Quedaremos a la espera de que se ofrezcan nuevos datos oficiales al respecto.

32. Datos obtenidos del estudio sobre la ciberseguridad y confianza en los hogares españoles, publicado en septiembre de 2018 por el Observatorio Nacional de las Telecomunicaciones y de la Sociedad de la Información (ONTSI), pp. 11 y 20. Disponible en: https://goo.gl/4dq11d. Última consulta: 24/12/2018. 
Esta obligación, sin embargo, no entraría en vigor hasta el 1 de enero de 2017, en virtud de la Disposición Final 12. ${ }^{\text {a }}$ de la Ley 42/2015, justo un año después de que entrara en vigor para las Oficinas Judiciales y Fiscales y los profesionales de la Justicia. Un plazo considerado razonable para que todos aquellos futuros obligados recibieran la formación adecuada, se abastecieran de todos los sistemas, dispositivos y herramientas electrónicas necesarias para la interacción electrónica y adecuaran el ejercicio de su profesión o cargo a la aplicación de los medios electrónicos. En cualquier caso, siguiendo lo dispuesto en el artículo 33.1 de la Ley 18/2011, de 5 de julio, se consideraba que se trataba de «personas jurídicas o colectivos de personas físicas que, por razón de su capacidad económica o técnica, dedicación profesional u otros motivos acreditados, tenían garantizado el acceso y disponibilidad de los medios tecnológicos precisos». ¿Ha sido así en todos los casos?

Situando nuestra atención, por ejemplo, en las personas jurídicas, los datos estadísticos arrojan evidencia sobre la existencia de desigualdades notorias respecto a la disposición y uso de los medios electrónicos entre las empresas de diez o más empleados y las más pequeñas, con menos de diez trabajadores ${ }^{33}$. Por un lado, mientras que el 98,7\% de las empresas de mayor volumen disponen de conexión a Internet, solo el 75,5\% de las pequeñas empresas declara disponer de dicho acceso. Respecto al uso de firma digital, los datos vuelven a ser desalentadores: aunque es cierto que en las grandes empresas se alcanza un buen nivel de empleo de dicha medida cualificada de seguridad $(76,7 \%)$, las pequeñas empresas presentan datos que dejan mucho que desear $(37,0 \%)$, sobre todo teniendo en cuenta que se encuentran obligados al uso de medios electrónicos en el ámbito jurisdiccional y que el uso de los sistemas de certificación y firma electrónica será esencial para ello.

En este aspecto, resultará fundamental, nuevamente, la actuación activa de los poderes públicos. Por un lado, consideramos que sería conveniente fomentar la implantación real y efectiva de las nuevas tecnologías y, en especial, de las medidas cualificadas de seguridad, en la actividad diaria de todos aquellos colectivos obligados a relacionarse por medios electrónicos, ya no solo con la Administración de Justicia, sino con todas las Administraciones Públicas ${ }^{34}$, de modo que, en su actuación ante ellas, se encuentren perfectamente familiarizados con su buen uso y funcionamiento. Por otro lado, para facilitar el acceso a aquellos sujetos obligados que, por sus circunstancias particulares vean dificultado su acceso a los servicios electrónicos, ofrecer una asistencia técnica y jurídica eficaz que pueda acompañarlos en la realización de los diversos trámites electrónicos. A estos efectos, destacamos la necesidad de habilitar teléfonos de atención ciudadana operativos en horario laboral e implantar en la Oficinas Judiciales puntos de información y asistencia presencial especializados en informática judicial. De lo que se trata es de que ningún justiciable se encuentre desamparado a la hora de acceder a la justicia electrónica y procurar que dispongan de aquellos conocimientos más básicos para operar en el entorno virtual en condiciones óptimas de seguridad, confianza y privacidad.

33. Datos obtenidos de la encuesta sobre el uso de las tecnologías de la información y la comunicación y el comercio electrónico en las empresas, publicada por el Instituto Nacional de Estadística el pasado 20 de septiembre de 2018. Disponible en: https://goo.gl/yogs6d. Última consulta: 24/12/2018.

34. La reciente Ley 39/2015, de 1 de octubre, reguladora del Procedimiento Administrativo Común de las Administraciones Públicas, trajo como novedad la introducción en su artículo 14.2 de un listado de sujetos obligados a relacionarse por medios electrónicos con las Administraciones Públicas para la realización de cualquier trámite de un procedimiento administrativo, los cuales coinciden, prácticamente, con los sujetos obligados en el ámbito jurisdiccional. 


\section{Las notificaciones judiciales electrónicas}

\subsection{La práctica de notificaciones por medios electrónicos}

Los actos de comunicación son actos de naturaleza procesal emanados del órgano judicial dirigidos a dar a conocer el contenido de una determinada resolución o actuación judicial a su legítimo destinatario.

Más allá de ser meros actos formales e instrumentales, los actos de comunicación son un elemento clave para la correcta formación de la relación jurídico-procesal ${ }^{35}$ y para la buena marcha del proceso hasta su definitiva terminación. Como sabemos, a través de ellos, se pone en conocimiento del demandado la existencia de un litigio iniciado en contra de él, lo que le sitúa en posición de comparecer y actuar en defensa de sus derechos e intereses legítimos. Asimismo, una vez personadas las partes, los actos de comunicación actúan como vehículo de las diversas resoluciones judiciales que se suceden a lo largo del proceso y operan como elemento impulsor de las actuaciones que deben llevarse a cabo, permitiendo a los intervinientes tener perfecto conocimiento de su contenido y proceder en consecuencia ${ }^{36}$.

La estrecha relación de estos actos con el ejercicio del derecho fundamental de defensa, así como con los principios de contradicción e igualdad de armas procesales, ha justificado que, en incontables ocasiones, tanto Tribunal Constitucional, como el Tribunal Supremo, nos recuerden su relevancia constitucional ${ }^{37}$. Debemos tener muy presente que, cuando hablamos de la necesaria observancia de las normas que rigen la práctica de las comunicaciones judiciales, no nos referimos a simples formalidades, sino a auténticas garantías ${ }^{38}$ que, en su conjunto, salvaguardan el derecho fundamental a recibir la tutela judicial efectiva de jueces y tribunales sin sufrir indefensión (art. $24 \mathrm{CE}$ ).

Dicho esto, trasladar estas garantías al terreno virtual se ha convertido en uno de los mayores retos a los que se enfrenta el legislador de forma continua. No debemos olvidar que los peligros de la Red se renuevan día a día a medida que avanza el estado de la técnica, y, como vemos, en el ámbito jurisdiccional, el margen de error y riesgo que se puede asumir, sin que se vean afectados derechos fundamentales, es muy estrecho.

La admisibilidad de los medios electrónicos para llevar a cabo las notificaciones judiciales, entendidas en un sentido amplio y comprensivo de todas las clases de actos procesales de comunicación (art. 149 LEC), se contempla, en primer lugar, en el artículo 271 LOPJ. De forma, a nuestro parecer, demasiado escueta, esta norma básica dispone: «las notificaciones podrán practicarse por medio del correo, del telégrafo o de cualquier medio técnico que per-

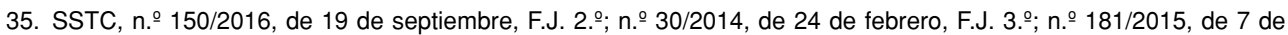
septiembre, F.J. 2.․; 186/2007, de 10 de septiembre, F.J. 2.o; 128/2000, de 16 de mayo; F.J. 5.o; 219/1999, de 29 de noviembre, entre otras muchas.

36. Cernada Badía (2016) se refiere a los actos de comunicación judicial como «elemento esencial de la publicidad procesal interna» (p. 189). Dicha dimensión interna de la publicidad en el proceso «garantiza el principio de contradicción, asegurando el conocimiento por las partes de los actos procesales» (p. 187).

37. Sobre la relevancia constitucional de los actos de comunicación procesal: Martín González, M. (2018), «Introducción a la doctrina constitucional sobre actos de comunicación», Revista Estudios Institucionales, UNED, vol. 5, n.ㅇ 9, pp. 213242. Revista digital: https://goo.gl/TnRmYm. Última consulta: 29/12/2018.

38. En este sentido: Yélamos Bayarri, E. (2006), Nulidad procesal y comunicaciones judiciales fallidas, Barcelona, Atelier, pp. 31-32. 
mita la constancia de su práctica y de las circunstancias esenciales de la misma según determinen las Leyes procesales». Al ser el precepto por el que se legitima el empleo de «medios técnicos» en la práctica de las comunicaciones judiciales, resulta, cuanto menos curioso que sea, asimismo, el único del Capítulo VII del Título III del Libro III de la LOPJ que no ha sido modificado en ninguna ocasión desde que fuera aprobada la Ley Orgánica en 1985.

Por su parte, la Ley de Enjuiciamiento Civil reconoce la validez de estos medios en su artículo 152.3. 2.ำ el cual dispone que los actos de comunicación podrán efectuarse, entre otras formas y según disponga la Ley, por «remisión de lo que haya de comunicarse mediante correo, telegrama, correo electrónico o cualquier otro medio electrónico que permita dejar en los autos constancia fehaciente de la recepción, de su fecha y hora y del contenido de lo comunicado".

Abierta la puerta a la tecnificación de las notificaciones judiciales, la cuestión que ahora nos ocupa es: ¿pueden los justiciables recibir notificaciones electrónicas directas y con plena eficacia jurídica?

En primer lugar, conviene matizar que, a diferencia de lo que ocurre en el ámbito de las Administraciones Públicas, en la esfera jurisdiccional, suelen ser los profesionales del Derecho quienes asumen la función y responsabilidad de recibir la gran mayoría de las notificaciones judiciales. En particular, en el orden civil, destacamos la figura del procurador de los tribunales ${ }^{39}$, quien se encarga de recibir todas las comunicaciones que se remiten a sus poderdantes a lo largo del proceso, exceptuando aquellos casos en los que su intervención no sea preceptiva y el litigante haya decidido comparecer por sí mismo (art. 23.2 LEC), así como aquellos demás supuestos en los que la Ley disponga que las comunicaciones deban practicarse a los litigantes en persona (art. 28.4 LEC). Este motivo nos lleva a afirmar que, en la práctica, serán limitadas las ocasiones en las que los actos de comunicación se practiquen sin la intervención de un profesional del Derecho ${ }^{40}$.

Volviendo a la cuestión que nos ocupa, el apartado 2. del artículo 152 LEC parece claro: «los actos de comunicación se practicarán por medios electrónicos cuando los sujetos intervinientes en un proceso estén obligados al empleo de los sistemas telemáticos o electrónicos existentes en la Administración de Justicia conforme al artículo 273, o cuando aquellos, sin estar obligados, opten por el uso de esos medios con sujeción, en todo caso, a las disposiciones contenidas en la normativa reguladora del uso de las tecnologías de la información y la comunicación [...]». Ello, por supuesto, siempre y cuando el acto no vaya acompañado de elementos que no sean susceptibles de conversión a formato electrónico y la Ley no disponga que se practiquen por otros medios.

Esta disposición fue introducida por ya mencionada Ley 42/2015, de 5 de octubre, la cual, con el fin de dotar de contenido a los derechos reconocidos en la Ley 18/2011, de 5 de

39. De conformidad con el artículo 28 LEC, los procuradores, en su condición de representantes procesales, tienen la obligación y responsabilidad de recoger y firmar todas las notificaciones y traslados que se remitan a sus poderdantes, teniendo esta actuación la misma eficacia que si hubieran sido recibidas personalmente por su destinatario. Por supuesto, se exceptúan aquellos actos de comunicación que, por disposición legal, deban practicarse a los litigantes en persona. Si bien esos casos son residuales.

40. Al respecto, Cernada Badía (2016) afirma que «así, frente al carácter directo de la relación establecida entre Administraciones Públicas y administrados, la mediatización de las relaciones entre ciudadanos y Administración de Justicia, canalizadas a través de profesionales (abogados y procuradores) condiciona la incorporación de las TIC a la Administración de Justicia» (p. 217). 
julio, realizó una reforma integral de nuestro sistema procesal de notificaciones, dotando de una cobertura legal completa a las comunicaciones judiciales practicas por medios técnicos, electrónicos, informáticos y telemáticos.

No obstante, y pese al espíritu de la Ley 42/2015 de abrir las puertas a la tecnificación de las comunicaciones, podemos recapitular varios ejemplos sobre la desconfianza del legislador en esta forma de dar a conocer a las partes el contenido de las diversas resoluciones y actuaciones judiciales que se suceden a lo largo del proceso. Así, el artículo 155 LEC: según su apartado 1., cuando los litigantes no actúen representados por procurador o se trate del primer emplazamiento o citación del demandado, los actos de comunicación se remitirán a su domicilio.

Una interpretación acorde con los principios de la reforma de 2015 debería ser favorable a la inclusión en el concepto de «domicilio» de las direcciones electrónicas. Ello supondría una auténtica reformulación del concepto tradicional de domicilio ad litem y refrendaría la validez legal de los buzones virtuales como «lugar» apto para la remisión de notificaciones judiciales perfectamente válidas y eficaces a aquellas partes procesales que actúen en el proceso por sí mismas. Sin embargo, la lectura completa de este artículo nos impide tomarnos tal licencia interpretativa, al menos por el momento. Tras manifestar una clara preferencia por los domicilios físicos que constan en registros oficiales ${ }^{41}$ (ap. $3 .{ }^{\circ}$ ), el artículo 155 LEC se refiere a los «números de teléfono, de fax, dirección de correo electrónico o similares» (únicos medios electrónicos indicados) como aquellos datos que pueden ser de utilidad para la localización del demandado (ap. 2.ํ), pero ¿y para su notificación?

Aunque, como veremos más adelante, podemos defender la validez del correo electrónico como medio de notificación eficaz y seguro, en dicho precepto, este canal de comunicación se enumera junto a otros dos no aptos, en absoluto, para la práctica de los actos de comunicación -el teléfono y el fax- ${ }^{42}$. En su virtud, a los efectos del presente artículo, no podemos entender que el legislador se refiera a ellos, además de como a datos que pueden facilitar la localización del demandado, como medio válido para la práctica de las comunicaciones que se le deban dirigir. Al respecto, Cernada Badía afirma que, si bien con respecto al primer emplazamiento podría quedar justificada tal prudencia por la implicación del derecho fundamental a la tutela judicial efectiva, «en efecto, podría cuestionarse el garantismo del legislador cuando limita la autonomía de la voluntad a la hora de elegir un domicilio de notificaciones, siempre que el medio elegido ofrezca, al menos, las mismas garantías que las de

41. En virtud del apartado 3. del artículo 155 LEC: «A los efectos de actos de comunicación podrá designarse como domicilio el que aparezca en el padrón municipal, o el que conste oficialmente a otros efectos, así como el que aparezca en el registro oficial o en publicaciones de colegios profesionales, cuando se tratare, respectivamente, de empresas y otras entidades o de personas que ejerzan profesión para la que deban colegiarse obligatoriamente. También podrá designarse como domicilio, a los referidos efectos, el lugar en que se desarrolle la actividad profesional o laboral no ocasional. Cuando en la demanda se ejercite una acción de aquellas a las que se refiere el número 1.ㅇ del apartado 1 del artículo 250.1, se entenderá que si las partes no han acordado señalar en el contrato de arrendamiento un domicilio en el que se llevarán a cabo los actos de comunicación, este será, a todos los efectos, el de la vivienda o local arrendado. Si la demanda se dirigiese a una persona jurídica, podrá igualmente señalarse el domicilio de cualquiera que aparezca como administrador, gerente o apoderado de la empresa mercantil, o presidente, miembro o gestor de la junta de cualquier asociación que apareciese en un registro oficial».

42. Cerrada Moreno, M. (2012), Actos de comunicación procesal y derechos fundamentales, Cizur Menor, Aranzadi, pp. 92-94. 
un emplazamiento postal» ${ }^{43}$. Para finalizar, curiosamente, se contempla la obligatoriedad de mantener actualizados los datos referidos a los medios de comunicación electrónicos señalados, «siempre que estén siendo utilizados como instrumentos de comunicación con la Oficina Judicial» (ap. 5. ${ }^{\circ}$ ). No obstante, este deber se establece de forma residual y complementaria a la obligación de mantener actualizado el domicilio.

Por supuesto, de lo anteriormente expuesto no debemos extraer la conclusión de que los ciudadanos no pueden optar por los canales electrónicos para la recepción de los actos de comunicación procesal. Pese a que el artículo 155 LEC evidencia la clara preferencia del legislador por el domicilio físico como sede idónea, lo cierto es que por defecto, para lograr la efectiva recepción de los actos de comunicación por sus legítimos destinatarios, no obsta para que, una vez personados, los justiciables comuniquen a la Oficina Judicial su preferencia por un medio electrónico determinado, válido y efectivo para la recepción de las sucesivas comunicaciones que se practiquen a lo largo del procedimiento, tal y como prescribe el párrafo segundo del apartado 1. del artículo 162 LEC. Ahora bien, ¿cuáles son los canales electrónicos disponibles?

De conformidad con los artículos 8 y 11 del Real Decreto 1065/2015, de 27 de noviembre, los ciudadanos que actúen por sí mismos en el proceso y opten por el uso de medios electrónicos para la recepción de sus notificaciones, dispondrán de los siguientes canales electrónicos: la sede judicial electrónica, a través de la cual se posibilitará, previa identificación del destinatario mediante certificado electrónico, el acceso al contenido de las resoluciones judiciales objeto de notificación, bien por medio de comparecencia electrónica, bien a través de una dirección electrónica habilitada -DEH_44 (arts. 21 y 22 RD 1065/2015); el servicio compartido de gestión de notificaciones electrónicas y la carpeta ciudadana, suministrados por el Ministerio de Hacienda y Administraciones Públicas, siempre que los medios tecnológicos lo permitan; y aquellos otros sistemas electrónicos de información y comunicación que puedan establecerse en un futuro.

Destacaremos, asimismo, el correo electrónico, cuyo uso se ha generalizado en el tráfico jurídico de forma exponencial, demostrando ser una herramienta de comunicación electrónica célere, eficaz y segura.

La validez de este canal para la recepción de actos de comunicación procesal se contempla expresamente en el número $2 .^{\circ}$ del apartado $3 .^{\circ}$ del artículo 152 LEC, así como en el artículo 24 del mencionado Real Decreto 1065/2015. No obstante, debemos señalar que encontramos dos disposiciones aparentemente contradictorias respecto a su validez en el

43. Cernada Badía (2016, p. 397).

44. Respecto al potencial de la dirección electrónica habilitada como canal de comunicación, destacamos la interesante propuesta realizada hace algunos años por Magro Servet, V. (2013): la creación de una dirección electrónica habilitada única para cada ciudadano de entre 18 y 70 años con residencia habitual en España de consulta obligatoria para la recepción con plenos efectos jurídicos de toda clase de notificaciones, tanto judiciales como administrativas. Propuso, asimismo, el establecimiento de áreas específicas para la consulta de las direcciones electrónicas en las dependencias de cada Administración, de modo que quienes no dispusieran de los dispositivos y sistemas necesarios, pudieran acceder periódicamente a su buzón virtual en condiciones de igualdad. Estaríamos, en definitiva, ante la generalización del uso de los medios electrónicos para la práctica de notificaciones a los justiciables y administrados. Si bien consideramos que aún queda mucho camino por recorrer en este sentido, se trata de una idea que no debemos perder de vista dada su posible virtualidad práctica en un futuro. En Magro Servet, V. (2013), «El domicilio electrónico como garantía de la agilización de los actos de comunicación entre la Administración pública y los ciudadanos», Diario La Ley, n.ㅇ 8131, Las Rozas, Madrid, Wolters Kluwer. 
mismo artículo 152 LEC. A pesar de que, como hemos señalado, el número 2. de su apar-

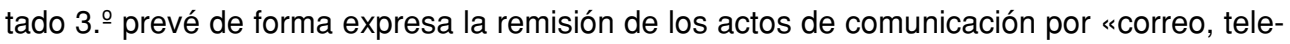
grama, correo electrónico o cualquier otro medio electrónico que permita dejar en los autos constancia fehaciente de la recepción, de su fecha y hora y del contenido de lo comunicado", el último párrafo de su apartado $2 . .^{\circ}$ establece que «el destinatario podrá identificar un dispositivo electrónico, servicio de mensajería simple o una dirección de correo electrónico que servirán para informarle de la puesta a su disposición de un acto de comunicación, pero no para la práctica de notificaciones». Paradójicamente, ambas referencias del artículo 152 LEC a este medio electrónico fueron introducidas por la Ley 42/2015, de 5 de octubre. Una forma de armonizar ambas disposiciones sería entender que se refieren a modalidades distintas de correo electrónico: por un lado, el apartado 2. se referiría al empleo del correo electrónico ordinario, sin garantías adicionales de seguridad, para la remisión de avisos sin eficacia jurídica; y, por otro lado, el apartado 3. admitiría el uso del correo electrónico para la remisión de actos de comunicación, siempre y cuando se dispusieran los medios necesarios para que dicho canal dejarse constancia fehaciente de la recepción, de su fecha y hora y del contenido de lo comunicado.

Como veremos a continuación, la validez de cualquier medio técnico, electrónico, informático y telemático que se emplee para la práctica de las notificaciones procesales se encontrará supeditada al cumplimiento de las exigencias técnicas que constituyen la piedra angular de la confianza y la seguridad en toda clase comunicación electrónica.

\subsection{Validez y eficacia de las notificaciones practicadas por medios electrónicos}

De conformidad con lo dispuesto en el artículo 162.1 LEC, todo medio a través del cual se pretenda practicar un acto de comunicación judicial deberá ser capaz de garantizar la autenticidad de la comunicación y de su contenido, así como dejar constancia fehaciente de la emisión y recepción íntegras y del momento en que tuvieron lugar. En otras palabras, los medios empleados deberán, en primer lugar, ofrecer certeza sobre la identidad de los intervinientes en la comunicación, esto es, certificar que quienes dicen haber enviado y recibido el mensaje, respectivamente, son quienes dicen ser; en segundo lugar, proteger la integridad del mensaje en su viaje por la Red, de manera que una persona distinta a su legítimo destinatario no pueda acceder a su contenido, ni mucho menos manipularlo; en tercer lugar, dejar constancia fehaciente de la emisión y de la recepción, así como del acceso al contenido, con reflejo exacto de la fecha y hora en que sucede cada acción; y por último, tener la capacidad de generar, de forma automática e independiente a la voluntad de los interlocutores, acuses de recibo acreditativos del día y hora en que tienen lugar la remisión del mensaje y la recepción íntegra de su contenido. Todos estos requisitos son los que convierten un canal de comunicación electrónico y telemático en un instrumento seguro y apto para transmitir con plena eficacia jurídica un acto de comunicación en el ámbito jurisdiccional, por lo que serán exigibles en cualquier caso y con independencia del medio electrónico que escojamos.

Respecto al cumplimiento de estos requisitos en el uso del correo electrónico, la Disposición Transitoria 2. ${ }^{a}$ del Real Decreto 1065/2015, en consonancia con lo dispuesto en su 
artículo 23, preceptúa que, cuando el ciudadano haya optado por este medio de comunicación con la Oficina Judicial, las notificaciones deberán remitirse a través de la sede judicial electrónica, en tanto el litigante no disponga de un sistema de correo que genere, por defecto y sin posibilidad de manipulación, un acuse de recibo acreditativo de la recepción y acceso al contenido del mensaje. En este aspecto, destacamos la idoneidad del correo electrónico certificado por empresa prestadora de servicios de confianza ${ }^{45}$, el cual, mediante el uso de certificados de firma electrónica y mecanismos de sellado de tiempo ${ }^{46}$, permite garantizar la integridad del mensaje y ofrecer constancia fehaciente de la identidad de los intervinientes en la conversación electrónica, así como de la fecha y hora exactas en las que han tenido lugar, tanto la remisión, como la recepción y la apertura del mensaje.

Este conocimiento fehaciente nos permitirá conocer con exactitud cuándo se tiene por válidamente efectuada una notificación y, por ende, cuándo empieza a desplegar sus efectos en la esfera procesal. Se trata, pues, de una pieza clave para la seguridad jurídica en las comunicaciones electrónicas.

Sentados los anteriores fundamentos, una vez conste el acceso al contenido por parte del destinatario, se tendrá por efectuada la comunicación y surtirá plenos efectos. Eso sí, la eficacia del acto de comunicación no quedará supeditada de forma indefinida a la intervención del receptor. En este sentido, el artículo 162.2 LEC establece que «cuando constando la correcta remisión del acto de comunicación por dichos medios técnicos [... $]^{47}$, transcurrieran tres días ${ }^{48}$ sin que el destinatario acceda a su contenido, se entenderá que la comunicación ha sido efectuada legalmente desplegando plenamente sus efectos». Por supuesto, quedan exceptuados aquellos casos en los que la falta de acceso se deba a una imposibilidad técnica, material o personal ${ }^{49}$, debidamente acreditada, en cuyo caso se estará a lo dispuesto en el párrafo 2. del artículo 162.2 LEC $^{50}$.

Ahora bien, esta no fue siempre la redacción del artículo 162.2 de la LEC. Con anterioridad a la reforma operada por la Ley $13 / 2009$, de 3 de noviembre, de reforma de la legisla-

45. A modo de ejemplo, podemos destacar los servicios de certificación de envíos ofrecidos por el Consejo General de Procuradores de España a través de su plataforma «Certificación Procuradores». Actuando como tercero de confianza, el Consejo General ofrece, tanto a particulares como a empresas, la posibilidad de realizar diversos tipos de notificaciones electrónicas certificadas a través del sellado de tiempo y la firma electrónica. Más información disponible en: https://goo.gl/Va8ncd. Última consulta: 26/12/2018.

46. De conformidad con la definición ofrecida por la FNMT-RCM, a través de su departamento CERES («CErtificación ESpañola»), en su web oficial, «el sellado de tiempo es un método para probar que un conjunto de datos existió antes de un momento dado y que ninguno de estos datos ha sido modificado desde entonces». Más información disponible en: https://goo.gl/VBe7xX. Último acceso: 26/12/2018.

47. Art. 162.2 LEC: «[...] Salvo los practicados a través de los servicios de notificaciones organizados por los Colegios de Procuradores [...]” a los que se les aplica un régimen específico.

48. Autores como Cernada Badía (2016, p. 422) han criticado, por breve, el plazo de tres días concedido a los destinatarios para acceder al contenido de la comunicación, comparado, por ejemplo, con el plazo de diez días naturales previsto en el artículo 43.2 de la Ley 39/2015, de 1 de octubre, para las notificaciones administrativas telemáticas.

49. Cernada Badía (2016, pp. 426-427).

50. «Se exceptuarán aquellos supuestos en los que el destinatario justifique la falta de acceso al sistema de notificaciones durante ese periodo. Si la falta de acceso se debiera a causas técnicas y estas persistiesen en el momento de ponerlas en conocimiento, el acto de comunicación se practicará mediante entrega de copia de la resolución. En cualquier caso, la notificación se entenderá válidamente recibida en el momento en que conste la posibilidad de acceso al sistema. No obstante, caso de producirse el acceso transcurrido dicho plazo, pero antes de efectuada la comunicación mediante entrega, se entenderá válidamente realizada la comunicación en la fecha que conste en el resguardo acreditativo de su recepción» (art. 162 LEC). 
ción procesal para la implantación de la nueva Oficina Judicial, su tenor literal disponía que, trascurridos tres días sin que el destinatario accediera a su contenido, se entendería que la comunicación había sido intentada sin efecto y se procedería a su entrega en la forma establecida en el artículo 161 LEC, esto es, por medio de la entrega personal de la copia de la resolución o cédula. Lo más preocupante del contenido de dicho precepto era que prácticamente dejaba en manos de la voluntad del destinatario el despliegue de efectos de las comunicaciones electrónicas ${ }^{51}$. El receptor tan solo tenía que despreocuparse de acceder a su buzón virtual correspondiente para dejar sin efecto cualquier notificación que pudiera recibir a través de dichos medios, dilatando de esta manera a su favor los tiempos del procedimiento y duplicando innecesariamente la carga de trabajo del personal al servicio de la Administración de Justicia. Si lo que se buscaba era introducir un nuevo modo más célere y efectivo de realizar los actos de comunicación, que son, precisamente, la principal causa de demora en los procesos $^{52}$, el legislador debía depositar verdadera confianza en estos medios y otorgarles la misma eficacia jurídica que a las notificaciones remitidas al domicilio en los términos del artículo 155 LEC y así se hizo ${ }^{53}$.

De esta forma, cuando el acto de comunicación se realice por remisión, ya sea por medios tradicionales (art. 160 LEC) o electrónicos (art. 162 LEC), la constancia de la correcta remisión permitirá tener por practicada la notificación -pasados tres días hábiles (art. 133.2 LEC) sin acceso al contenido en el caso de las comunicaciones electrónicas-y surtirá plenos efectos, sin necesidad de que conste su recepción por el destinatario (arts. 155.4 y 162.2 LEC). En este aspecto, resultará de gran ayuda para los justiciables que decidan interactuar por medios electrónicos con la Administración de Justicia, configurar avisos en sus dispositivos, teléfonos móviles o direcciones de correo electrónico para conocer de forma inmediata la puesta a disposición de notificaciones (art. 152.2 LEC y art. 25 RD 1065/2015). Eso sí, conviene destacar que, tal y como dispone el artículo 152.2 LEC, «la falta de práctica de este aviso no impedirá que la notificación sea considerada plenamente válida», por lo que habrá que tener cuidado con los posibles fallos del sistema de avisos.

Sin perjuicio de lo anteriormente expuesto, debe matizarse que dicho despliegue de efectos automático no será de aplicación cuando la notificación tenga por objeto la personación en juicio o la intervención personal de las partes en determinadas actuaciones procesales (arts. 155.4 y 158 LEC). En estos casos, dada la trascendencia que tiene para el ejercicio del derecho fundamental de defensa el efectivo conocimiento del contenido de la notificación procesal, se establece como garantía un segundo intento preceptivo de notificación mediante entrega personal, en la forma prevista en el artículo 161 LEC, tras un intento de remisión con resultado negativo (art. 158 LEC).

Resulta curioso que no encontremos esta matización en el artículo 162.2 LEC cuando se refiere a la eficacia de los actos de comunicación por medios electrónicos, informáticos y

51. En este sentido, Cernada Badía (2016, p. 418).

52. Álvarez-Buylla Ballesteros, M. (2012), «Los defectos endémicos del proceso y de la Administración de Justicia Española», Práctica de Tribunales, n.o 96-97, Madrid, Wolters Kluwer, p. 96.

53. De conformidad con el artículo 155.4 LEC: «Si las partes no estuviesen representadas por procurador, las comunicaciones efectuadas en cualquiera de los lugares previstos en el apartado anterior, que se hayan designado como domicilios, surtirán plenos efectos en cuanto se acredite la correcta remisión de lo que haya de comunicarse, aunque no conste su recepción por el destinatario». 
similares. ¿Debe aplicarse lo dispuesto en los artículos 155.4 y 158 LEC, por analogía, a las notificaciones electrónicas, al tratarse también de una modalidad de remisión? ¿O es que el legislador ha querido dar a entender que aquellas comunicaciones que tengan por objeto la personación en juicio o la intervención personal de las partes en determinadas actuaciones procesales no pueden practicarse por medios electrónicos? Como comentábamos anteriormente respecto al concepto de domicilio al que se refiere el artículo $155 \mathrm{LEC}$, el legislador da muestras de cierta desconfianza hacia el empleo de las nuevas tecnologías para la realización de actuaciones tan fundamentales como el primer emplazamiento o citación al demandado, no obstante, es cierto que existen razones que podrían justificar la realización de estos actos de comunicación por medios tradicionales.

En primer lugar, pensemos que es el ciudadano, en su derecho a elegir la forma a través de la que quiere relacionarse con la Administración de Justicia, quien debe optar por dicha vía en lugar de la presencial. Lógicamente, cuando se procede a la práctica del primer emplazamiento, la Oficina Judicial no tiene conocimiento de las preferencias del demandado, por lo que recurre, por defecto, al canal presencial en virtud del art. 155 LEC. Debemos tener en cuenta, además, que los canales electrónicos disponibles son muy variados, y es el ciudadano quien tiene el derecho a optar por unos u otros, y quien debe comunicar su decisión a la Oficina Judicial en el momento procesal oportuno. En este sentido, el demandante tampoco estaría legitimado para indicar en el escrito de demanda una dirección electrónica concreta en la que practicar el primer emplazamiento pues, con esta designación, estaría eligiendo por el demandado, y podría situarle, consciente e inconscientemente, en una situación de indefensión. Además, recordemos la obligación del actor de señalar, como domicilio del demandado, a efectos del primer emplazamiento o citación de este, uno o varios de los lugares de aquellos a los que se refiere artículo 155.3 LEC, en el que, como señalamos con anterioridad, no se hace ninguna referencia a las direcciones electrónicas. Todo ello dificulta, e incluso imposibilita, la imposición de la vía electrónica por defecto en la práctica de actos de comunicación tan esenciales y vinculados al derecho de defensa como es el primer emplazamiento al demandado.

Una tendencia distinta se empieza a constatar en el ámbito de las Administraciones Públicas, donde la Ley 39/2015 ha sentado las bases para hablar de la preferencia de la vía electrónica ${ }^{54}$, aunque los ciudadanos siguen conservando su derecho a elegir entre la vía presencial y la electrónica (art. 14 Ley 39/2015) 55 . Ahora bien, como advierte Cotino Hueso (2012), «cuando se trata de la Administración en general, la relación del ciudadano con la misma no queda en general imbricada de un derecho fundamental. En cambio, en la relación del ciudadano con la Administración de Justicia de natural está implicado con mayor o menor intensidad el derecho fundamental del artículo 24 CE» (pp. 3-4).

A nuestro parecer, el nivel de generalización e implantación de las tecnologías de la información y la comunicación entre la ciudadanía para la gestión de sus relaciones con la Administración de Justicia se encuentra aún en un estado embrionario; existen aún impor-

54. En virtud del artículo 41.1 de la Ley 39/2015, «las notificaciones se practicarán preferentemente por medios electrónicos y, en todo caso, cuando el interesado resulte obligado a recibirlas por esta vía».

55. Cotino Hueso, L. (2018), «La obligación de relacionarse electrónicamente con la Administración y sus escasas garantías», Revista de Internet, Derecho y Política IDP, n. 26, p. 5. Revista electrónica disponible en: https://goo.gl/ NmnCsz. Última consulta: 26/12/2018. 
tantes sectores de la sociedad que no acceden en condiciones de igualdad a los servicios electrónicos ofrecidos. Es pronto para hablar de la vía electrónica por defecto y más, en un ámbito como el procesal, donde se ven directamente afectados derechos como el derecho de defensa, integrado en el derecho fundamental a la tutela judicial efectiva del artículo 24 de nuestra Constitución.

¿Qué ocurre, entonces, si a quien debe dirigirse el primer emplazamiento es uno de los sujetos obligados al uso de medios electrónicos (art. 273 LEC)? Nos encontramos con algunos de los inconvenientes señalados anteriormente. En primer lugar, el actor, quien tiene la obligación de indicar un domicilio a efectos de notificaciones, deberá indicar un domicilio de entre aquellos señalados en el artículo 155.3 LEC y, aun pudiendo designar un «domicilio virtual», es poco probable que tenga conocimiento de la dirección electrónica habilitada específica con la que el sujeto obligado ha decidido relacionarse de forma electrónica con la Administración de Justicia. Entendemos que será el sujeto obligado quien, en su primera comparecencia, que deberá ser electrónica ${ }^{56}$, identifique el canal a través del cual se relacionará con la Oficina Judicial desde ese momento. En este sentido, el artículo 162.1 LEC dispone que «los profesionales y destinatarios obligados a utilizar estos medios, así como los que opten por los mismos, deberán comunicar a las Oficinas Judiciales el hecho de disponer de los medios antes indicados y la dirección electrónica habilitada al efecto».

Ello será necesario, al menos, hasta que los órganos jurisdiccionales comiencen a disponer de bases de datos oficiales con las direcciones electrónicas habilitadas de todos los sujetos obligados, al igual que ocurre con los profesionales de la justicia.

\section{Conclusiones}

La modernización de la Administración de Justicia a través de la implantación de las nuevas tecnologías en el funcionamiento diario de las Oficinas Judiciales y Fiscales ha traído consigo ventajas constatables, entre las que podemos destacar: la simplificación de diversos trámites procesales, como las comunicaciones judiciales, con la consiguiente reducción del tiempo de tramitación de los procedimientos, así como de su coste económico; una mayor eficiencia en la gestión de los procesos; y, por supuesto, el acercamiento del ciudadano a la justicia, reforzando, con ello, su confianza en nuestro sistema judicial como medio de resolución célere y efectivo de conflictos.

Esta tecnificación ha permitido ofrecer al justiciable un nuevo canal para interactuar con los órganos jurisdiccionales: el electrónico. En este sentido, la Ley 18/2011, de 5 de julio, se erigió como hito normativo al reconocer por primera vez en una norma de rango de Ley el derecho subjetivo de todos los ciudadanos a relacionarse electrónicamente con la Administración de Justicia. Desde entonces, los esfuerzos del legislador y de las Administraciones con competencia en materia de justicia han estado dirigidos a dotar de contenido en el plano fáctico y jurídico a dicho derecho. Si bien aún queda mucho camino por recorrer, debemos reconocer el avance alcanzado hasta el momento, por ejemplo, con la puesta en marcha de

56. En cualquier caso, el incumplimiento de dicho deber del uso de las tecnologías previsto en el artículo 273.3 LEC, conllevará que el letrado de la Administración de Justicia conceda un plazo máximo de cinco días para su subsanación. Si no se subsana en este plazo, los escritos y documentos se tendrán por no presentados a todos los efectos. 
las sedes judiciales electrónicas, a través de las cuales se canalizará el acceso de los justiciables a los diversos servicios electrónicos que se vayan ofreciendo a medida que avance el estado de implementación de las TIC en el ámbito jurisdiccional.

Desde luego, no estamos ante un objetivo sencillo. Como hemos puesto de manifiesto a lo largo de nuestro estudio, alcanzar una justicia tecnológicamente avanzada y presidida por las relaciones electrónicas entre sus usuarios requerirá de una actuación proactiva por parte de los poderes públicos. En primer lugar, se deberá procurar que todas las Oficinas Judiciales y Fiscales dispongan de los medios materiales y humanos necesarios para asumir dicha digitalización, y, por supuesto, deberá ofrecerse al personal al servicio de la Administración de Justicia una formación adecuada y suficiente para el desempeño de sus funciones por medios electrónicos, procurándoles, asimismo, una asistencia técnica rápida y especializada en su día a día.

Otro factor fundamental, será lograr la plena disponibilidad y operatividad de los distintos canales electrónicos a través de los cuales los ciudadanos, en general, y los profesionales de la justicia y demás sujetos obligados en particular, se relacionarán con la Administración de Justicia. Cuestión en la que también ocupará un papel esencial la elaboración y difusión de manuales de usuario y buenas prácticas específicos y adecuados al nivel técnico de cada grupo de usuarios, de acceso libre y gratuito, con especial incidencia en la importancia de adoptar medidas cualificadas de seguridad en el entorno digital.

Al tiempo, y más allá de la existencia e idoneidad de los medios técnicos, otro desafío es el de dotar a la totalidad de estos avances de un marco normativo adecuado que garantice, por un lado, el respeto a los principios y garantías procesales que inspiran nuestro Derecho procesal y, por otro, la protección de los derechos fundamentales en juego, como el derecho fundamental a la tutela judicial efectiva (art. $24 \mathrm{CE}$ ). En este sentido, resultará esencial que los departamentos de desarrollo tecnológico e informática judicial cuenten con el apoyo de un asesor jurídico que guíe el avance informático, no solo hacia la perfecta armonización de las nuevas tecnologías con el ordenamiento jurídico procesal, sino hacia la resolución de los problemas concretos a los que se enfrenta diariamente la Administración de Justicia.

Respecto a las notificaciones procesales electrónicas, cabe destacar su función agilizadora. Como sabemos, el tiempo dedicado a la práctica de los actos de comunicación dirigidos a las partes aún no personadas o no representadas por procurador constituye una parte importante en la duración total de los procesos. Los medios electrónicos nos permitirán, en la forma y con las garantías previstas por las normas procesales reguladoras de estos actos, realizar gran parte de las comunicaciones judiciales dirigidas a aquellos justiciables que comparezcan y actúen en el proceso por sí mismos, de forma directa, inmediata y con plena eficacia jurídica.

\section{Bibliografía}

Álvarez-Buylla Ballesteros, M. (2012), «Los defectos endémicos del proceso y de la Administración de Justicia Española», Práctica de Tribunales, n. 96-97, La Ley, Madrid: Wolters Kluwer, pp. 96-105.

Cernada Badía (2016), «La notificación judicial electrónica: garantía del derecho fundamental a la tutela judicial efectiva y retos que plantea a la Administración de Justicia en España», Tesis Doctoral dirigida por el Dr. Lorenzo Cotino Hueso, Facultad de Derecho de la Universidad de Valencia, Valencia, 2016. Disponible en: https://goo.gl/gDJFJc. Última consulta: 29/12/2018 
Cerrada Moreno, M. (2012), Actos de comunicación procesal y derechos fundamentales, Navarra: Cizur Menor, Aranzadi.

Cerrillo-i-Martínez, A. (2011), “¿Cómo facilitar el ejercicio de los derechos de los ciudadanos en la Administración electrónica?», Revista de Internet, Derecho y Política IDP, n.ำ13, pp. 31-43. Revista electrónica disponible en: https://goo.gl/Wx67Dp. Última consulta: 26/12/2018.

Cotino Hueso, L. (2010), «El derecho a relacionarse electrónicamente con las Administraciones y el estatuto del ciudadano e-administrado en la Ley 11/2007 y la normativa de desarrollo", en Gamero Casado, E. y Valero Torrijos, J. (coord.), La Ley de Administración electrónica. Comentario sistemático a la Ley 11/2007, de 22 de junio, de acceso electrónico de los ciudadanos a los Servicios Públicos, Navarra: Cizur Menor, Aranzadi, 3. a edición, pp. 177-344.

Cotino Hueso, L. y Montesinos García, A., (2012) «Derechos de los ciudadanos y los profesionales en las relaciones electrónicas con la Administración de Justicia», en Valero Torrijos, J. y Gamero Casado (coord.), Las tecnologías de la información y la comunicación en la administración de justicia: análisis sistemático de la Ley 18/2011, de 5 de julio, Navarra: Cizur Menor, Aranzadi, pp. 181-228.

Cotino Hueso, L. (2018), «La obligación de relacionarse electrónicamente con la Administración y sus escasas garantías", Revista de Internet, Derecho y Política IDP, n.ำ 26, p. 5. Revista electrónica disponible en: https://goo.gl/NmnCsz. Última consulta: 26/12/2018.

Fundación Telefónica (2009), Las TIC en la Justicia del futuro, Colección Fundación Telefónica, Cuaderno 21, Madrid: Ariel.

González Campo, F. (2012), «Configuración procesal del Expediente Judicial Electrónico: Hacia un Derecho procesal electrónico", en Bueno de Mata, F. (coord.), FODERTICS: Estudios sobre Derecho y Nuevas Tecnologías, Santiago de Compostela: Andavira, pp. 201-216.

Magro Servet, V. (2013), «El domicilio electrónico como garantía de la agilización de los actos de comunicación entre la Administración pública y los ciudadanos», Diario La Ley, n.ํ 8131, Las Rozas, Madrid: Wolters Kluwer.

Martín González, M. (2018), «Introducción a la doctrina constitucional sobre actos de comunicación», Revista Estudios Institucionales, UNED, vol. 5, n. 9, pp. 213-242. Revista digital disponible en: http://revistas.uned.es/index.php/EEll/index. Última consulta: 29/12/2018.

Mira Ros, C. (2012) «Algunas reflexiones sobre la protección de datos personales en el ámbito judicial», Repositorio Universidade da Coruña. Disponible en: https://goo.gl/zJL9wf. Última consulta: 29/12/2018.

Simón Castellano, P (2012), «El derecho a la relación electrónica con la Administración de Justicia con la Ley 18/2011: un estudio crítico», en Bueno de Mata, F. (coord.), FODERTICS: Estudios sobre Derecho y Nuevas Tecnologías, Santiago de Compostela: Andavira, pp. 373-384.

Yélamos Bayarri, E. (2006), Nulidad procesal y comunicaciones judiciales fallidas, Barcelona: Atelier. 